\title{
Uncatalyzed Hydrogenation of First-Row Main Group Multiple Bonds
}

\author{
Merle Arrowsmith, Julian Böhnke, Holger Braunschweig, * Mehmet Ali Celik, Theresa Dellermann and Kai
}

Hammond

\begin{abstract}
Room temperature hydrogenation of an SIDep-stabilized diboryne (SIDep = 1,3-bis(diethylphenyl)-4,5-dihydroimidazol-2-ylidene) and a CAAC-supported diboracumulene (CAAC $=1-(2,6-$ diisopropylphenyl)-3,3,5,5-tetramethylpyrrolidin-2-ylidene) provided the first selective route to the corresponding 1,2-dihydrodiborenes. DFT calculations showed an overall exothermic $\left(\Delta G=19.4 \mathrm{kcal} \mathrm{mol}^{-1}\right)$ two-step asynchronous $\mathrm{H}_{2}$ addition mechanism proceeding via a bridging hydride.
\end{abstract}

Since the pioneering work of Sabatier over a century ago ${ }^{[1]}$ catalytic hydrogenation has become the most used reaction type in industrial chemical synthesis ${ }^{[2]}$ and still constitutes one of the most active research areas in chemistry. While the vast majority of industrial hydrogenation processes are based on well-established heterogeneous late transition metal catalysts $(\mathrm{Pt}, \mathrm{Pt}, \mathrm{Rh}, \mathrm{Ru}, \mathrm{Ni})^{[2]}$ the last decade has seen a revival of the field with the advent of metal-free frustrated Lewis pair catalysts capable of activating $\mathrm{H}_{2}{ }^{[4]}$ and transfer hydrogenation ${ }^{[5]}$ for the reduction of polar multiple bonds.

In contrast, catalyst-free hydrogenation reactions remain a rarity. Though feasible, the uncatalyzed hydrogenation of unsaturated hydrocarbons, whose main application lies in industrial direct coal liquefaction processes, requires exceptionally harsh reaction conditions $\left(400-500{ }^{\circ} \mathrm{C}, 150-300 \mathrm{~atm} \mathrm{H}_{2}\right)$ and, as a result, is highly unselective. ${ }^{[6]}$ The selective uncatalyzed hydrogenation of styrene derivatives and polycyclic aromatic systems has also been achieved at high temperatures using transfer hydrogenation, with 9,10dihydroanthracene as the $\mathrm{H}_{2}$-donor source, the reaction being driven by the re-aromatization of the sacrificial anthracene substrate. ${ }^{[7]}$ More recently hydrazine was successfully used as $\mathrm{H}_{2}$-donor for the uncatalyzed, photodriven transfer hydrogenation of unactivated olefins under ambient conditions in air, with $\mathrm{N}_{2}$ being the sole by-product of the reaction. ${ }^{[8]}$ Mild catalyst-free direct hydrogenation reactions of unsaturated hydrocarbons, however, unknown due to extremely high activation barriers. ${ }^{[8]}$

This is in contrast to the heavier p-block alkene and alkyne analogues, in which the frontier molecular orbitals are separated by more modest energies, making them more reactive toward small molecules. In 2005 Power and co-workers showed that a terphenylsupported digermyne underwent room temperature hydrogenation at atmospheric pressure, albeit unselectively, yielding a mixture of mono-, di- and trihydrogenated species. ${ }^{[10]}$ Using even more sterically demanding amido ligands, Jones and co-workers succeeded in selectively monohydrogenating a digermyne to the corresponding 1,2dihydrodigermene below $0{ }^{\circ} \mathrm{C} .{ }^{[11]}$ Power and co-workers also showed

[*] Dr. M. Arrowsmith, J. Böhnke, Prof. Dr. H. Braunschweig, Dr. M. A. Celik, T. Dellermann, K. Hammond Institute for Sustainable Chemistry \& Catalysis with Boron, and the Institute for Inorganic Chemistry Julius-Maximilians-Universität Würzburg Am Hubland, 97074 Würzburg (Germany)

E-mail: h.braunschweig@uni-wuerzburg.de Website: http://www.braunschweiggroup.de

Supporting information for this article is available on the WWW under that distannynes and digallenes may be selectively hydrogenated under mild conditions, albeit with concomitant cleavage of the $\mathrm{Sn}-\mathrm{Sn}$ or $\mathrm{Ga}-$ $\mathrm{Ga}$ bond, resulting in the formation of hydride-bridged stannane and gallane dimers, respectively. ${ }^{[12]}$

Low-valent mononuclear species of the $2^{\text {nd }}$ period have also shown promise as candidates for spontaneous hydrogenation. Most prominently, Bertrand and co-workers reported hydrogen activation at the singlet carbene carbon center of cyclic and acyclic (alkyl)(amino)carbenes (cAACs and aAACs). ${ }^{[13]}$ More recently, Stephan and Bertrand also reported $\mathrm{H}_{2}$ addition across the $\mathrm{B}-\mathrm{C}_{\mathrm{CAAC}}$ bond of a divalent cAAC-supported borylene, postulated to proceed via borylene-mediated $\mathrm{H}_{2}$ splitting followed by 1,2-hydride migration to the carbene carbon atom. ${ }^{[14]}$

The last decade has seen rapid advances in the synthesis and chemistry of reactive boron-boron bonded compounds. ${ }^{[15]}$ Recent efforts in our group have focused on the uncatalyzed activation of small molecules by boron-boron multiple bonds, including the direct hydroboration of N-heterocyclic carbene (NHC) stabilized 1,2diaryldiborenes, ${ }^{[16]}$ the reductive insertion of elemental chalcogens by NHC-supported diborynes ${ }^{[17]}$ the activation of tert-butylisocyanide and $\mathrm{CO}$ by a cAAC-supported diboracumulene ${ }^{[18]}$, the reductive coupling of four CO molecules by NHC-supported diborynes ${ }^{[18]}$ and, most recently, the cycloaddition of apolar alkynes to boron-boron multiple bonds. ${ }^{[20]}$ In this contribution we now report the facile and selective hydrogenation of B-B multiple bonds to the corresponding 1,2-dihydrodiborenes, making these the first examples of spontaneous $\mathrm{H}_{2}$ activation by lighter alkene and alkyne analogues.

First isolated by Robinson and co-workers, NHC-supported 1,2dihydrodiborenes, (IDip) ${ }_{2} \mathrm{~B}_{2} \mathrm{H}_{2}$ (1) and (IMes) ${ }_{2} \mathrm{~B}_{2} \mathrm{H}_{2}$ (2) (IDip $=1,3$ bis(2,6-diisopropylphenyl)imidazol-2-ylidene, $\mathrm{IMes}=1,3$-bis(2,4,6trimethylphenyl)imidazol-2-ylidene), were obtained from the reduction of (IDip) $\mathrm{BBr}_{3}$ with $\mathrm{KC}_{8}, \quad$ alongside the corresponding tetrahydrodiboranes(6), (IDip) ${ }_{2} \mathrm{~B}_{2} \mathrm{H}_{4}$ and (IMes) ${ }_{2} \mathrm{~B}_{2} \mathrm{H}_{4}$, both resulting from hydrogen atom abstraction from the reaction solvent by radical intermediates (Scheme 1). ${ }^{[21]}$ There has, however, been no report of a rational selective synthetic route toward 1,2-dihydrodiborenes.

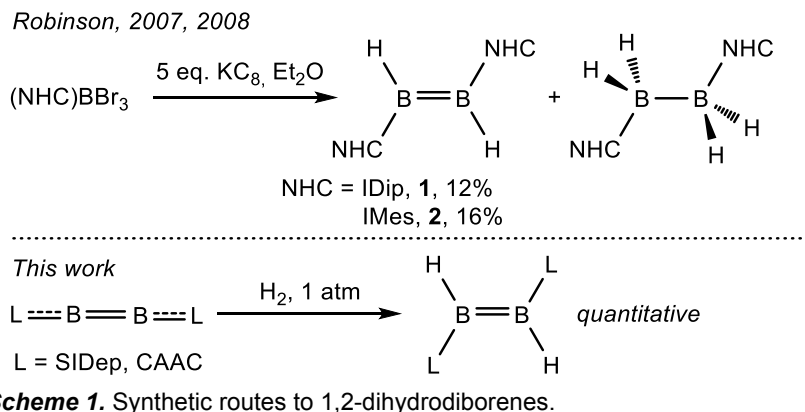

In light of the facile hydrogenation of digermynes ${ }^{[10]}$ attempts were made to hydrogenate diboryne $\mathbf{3 a}$, (IDip) ${ }_{2} \mathrm{~B}_{2},{ }^{[22]}$ in order to access the corresponding 1,2-dihydrodiborene, $\mathbf{1}$ (Scheme 2a). While no reaction was observed at room temperature under an atmosphere of $\mathrm{H}_{2}$, higher temperatures invariably led to irreproducible mixtures of $\mathrm{BH}$ containing products and $\mathrm{B}-\mathrm{B}$ bond cleavage, as observed by ${ }^{11} \mathrm{~B}$ NMR 
spectroscopy. While the boron-bound hydrides were, at first, assumed to originate from $\mathrm{H}_{2}$ activation by the $\mathrm{B} \equiv \mathrm{B}$ triple bond, experiments using ultra-pure $\mathrm{D}_{2}$ in perdeuterated solvents also resulted in the exclusive formation of $\mathrm{B} H$-rather than $\mathrm{B} D$-containing species. It thus became apparent that, under the harsh reaction conditions used, $\mathrm{C}-\mathrm{H}$ activation of the IDip ligand by the $\mathrm{B} \equiv \mathrm{B}$ triple bond was occurring, rather than $\mathrm{H}_{2}$ activation. In order to verify whether steric shielding of the $\mathrm{B} \equiv \mathrm{B}$ unit may be preventing hydrogenation of $\mathbf{3 a}$, a solution of the less sterically hindered (IDep) ${ }_{2} \mathrm{~B}_{2}$ derivative, $\mathbf{3 b},{ }^{[23]}$ was also heated under an atmosphere of $\mathrm{H}_{2}$, with similar results (Scheme 2a).

Previous studies in our group have shown that the cAACsupported diboracumulene 5 , (cAAC) ${ }_{2} \mathrm{~B}_{2}$ (in this case cAAC $=1-(2,6-$ diisopropylphenyl)-3,3,5,5-tetramethyl-pyrrolidin-2-ylidene), while formally analogous to its NHC counterpart 3a, may best be described as a diboracumulene presenting a $\mathrm{C} \cdots \mathrm{B}=\mathrm{B} \cdots \mathrm{C}$ bonding motif, rather than a diboryne. ${ }^{[2]}$ This is due to the considerably increased $\sigma$-donor and additional $\pi$-acceptor properties of cAACs resulting from replacement of one of the $\pi$-donor amino groups adjacent to the carbene carbon center by a purely $\sigma$-donor alkyl group. ${ }^{[25]}$ As a result 5 also displays distinctly divergent reactivity towards $\mathrm{CO}$ than $\mathbf{3 a} .^{[18]}$

a)

$$
\begin{gathered}
\mathrm{L}-\mathrm{B} \equiv \mathrm{B}-\mathrm{L} \\
\mathrm{L}=\mathrm{IDip}, \mathbf{3 a} \\
\text { IDep, 3b } \\
\text { SIDip, 4a }
\end{gathered}
$$

$$
\text { b) }
$$

$$
\text { CAAC }=\mathrm{B}=\mathrm{B}=\mathrm{CAAC} \frac{\mathrm{H}_{2,1} \mathrm{~atm}}{\mathrm{C}_{6} \mathrm{H}_{6,} \mathrm{rt}, 1 \text { day }} \underset{\mathrm{CAAC}}{\stackrel{\mathrm{C}}{\longrightarrow}}
$$

$$
{ }_{A r=\operatorname{Dip}\left(2,6-{ }^{i} \mathrm{Pr}_{2} \mathrm{C}_{6} \mathrm{H}_{3}\right) ; \operatorname{Dep}\left(2,6-\mathrm{Et}_{2} \mathrm{C}_{6} \mathrm{H}_{3}\right)}^{\mathrm{IAr}}
$$$$
\text { increasing } \mathrm{l} \text {-acidity and } \mathrm{l} \text {-donation }
$$

Scheme 2. Reactivity of $\mathrm{L}_{2} \mathrm{~B}_{2}$ species with $\mathrm{H}_{2}$.

A benzene solution of 5 placed under an atmosphere of $\mathrm{H}_{2}$ underwent a color change from deep red to blue overnight at room temperature. Examination of ${ }^{11} \mathrm{~B}$ NMR data showed complete consumption of $\mathbf{5}$ and the appearance of a single new resonance at $40.7 \mathrm{ppm}$, ca $40 \mathrm{ppm}$ upfield from that of $5,{ }^{[24]}$ but still significantly downfield from that of its NHC analogue, $\mathbf{1}(25.3 \mathrm{ppm}) \cdot{ }^{[21]}{ }^{1} \mathrm{H}\left\{{ }^{11} \mathrm{~B}\right\}$ NMR data also evidenced a new broadened resonance at $5.05 \mathrm{ppm}$ integrating at $2 \mathrm{H}$ in relation to the resonances of the two equivalent cAAC ligands. Slow evaporation of the solvent yielded blue crystals (74\% isolated yield) which, upon $\mathrm{X}$-ray diffraction analysis, revealed the structure of the desired 1,2dihydrodiborene, (cAAC) ${ }_{2} \mathrm{~B}_{2} \mathrm{H}_{2}$ (7) (Fig. 1b). The boron-bound hydrides were located in the difference Fourier map and freely refined. Like its NHC analogue, $\mathbf{1},{ }^{[21]}$ compound 7 presents a planar $(\mathrm{C} 1 \mathrm{~B} 1 \mathrm{H} 1)_{2}$ core with the hydrides in trans-conformation but, unlike $\mathbf{1}$, the structure is $C_{2}$-symmetric. The mean plane of the cAAC ligand framework is twisted ca. $16^{\circ}$ from the $(\mathrm{C} 1 \mathrm{~B} 1 \mathrm{H} 1)_{2}$ plane. Owing to the $\pi$-acceptor properties of the cAAC ligands, which withdraw electron density from the diborene double bond, the $\mathrm{B}-\mathrm{B}$ bond length [1.625(2) $\AA]$ is rather elongated compared to those in the planar 1,2dihydrodiborene NHC derivative 1 [1.560(18) $\AA]^{[21]}$ but still considerably shorter than that of the unique trans-bent conformer of 2
$[1.679(9) \AA] .{ }^{[21]}$ Furthermore, the $\mathrm{B}-\mathrm{C}_{\text {carbene }}$ bond $[1.545(2) \AA]$ is ca. $0.9 \AA$ longer than that of the parent diboracumulene, $5,{ }^{[24]}$ indicating a substantial reduction in $\pi$-backbonding. Quantitative deuteration of 5 to the corresponding 1,2-deuterodiborene, $(\mathrm{cAAC})_{2} \mathrm{~B}_{2} \mathrm{D}_{2}$, was achieved using ultrapure $\mathrm{D}_{2}$, thus precluding $\mathrm{C}-\mathrm{H}$ activation as the origin of the boron-bound hydrides.

Experimental and computational data have shown that a diboryne supported by NHC ligands comprising a saturated backbone, such as (SIDip) ${ }_{2} \mathrm{~B}_{2} \quad$ (4a) $\quad$ (SIDip = 1,3-bis(2,6-diisopropylphenyl)-4,5dihydroimidazolin-2-ylidene), presents a bonding situation and reactivity intermediate between that of $\mathbf{3}$ and $\mathbf{5},{ }^{[18]}$ which may be ascribed to the mildly $\pi$-acidic nature of SIDip. ${ }^{[25]}$ Whereas $\mathbf{4 a}$ did not react with $\mathrm{H}_{2}$ even at elevated temperatures (Scheme 2a), its less sterically hindered analogue, SIDep (4b) (SIDep $=1,3$-bis $(2,6-$ diethylphenyl)-4,5-dihydroimidazolin-2-ylidene), prepared in a manner analogous to 4a (see Fig. S16 for the crystal structure of 4b) ${ }^{[18]}$ underwent slow hydrogenation to (SIDep) ${ }_{2} \mathrm{~B}_{2} \mathrm{H}_{2}(6)$ at $80{ }^{\circ} \mathrm{C}$ over a period of two days (Scheme $2 b$ ), as evidenced by the disappearance of the diboryne ${ }^{11} \mathrm{~B}$ NMR resonance at $55.9 \mathrm{ppm}$ and the appearance of a broad resonance at $28.1 \mathrm{ppm}$, similar to that observed for 1. ${ }^{[21]}$ The ${ }^{1} \mathrm{H}$ NMR $\mathrm{BH}$ resonance at ca. $2.6 \mathrm{ppm}$ was found to overlap with the ethyl $\mathrm{CH}_{2}$ multiplet and was later confirmed by ${ }^{2} \mathrm{H}$ NMR spectroscopy in the deuterated species, (SIDep) ${ }_{2} \mathrm{~B}_{2} \mathrm{D}_{2}$, obtained from the reaction of $\mathbf{4 b}$ with ultrapure $\mathrm{D}_{2}$.

\section{a)}
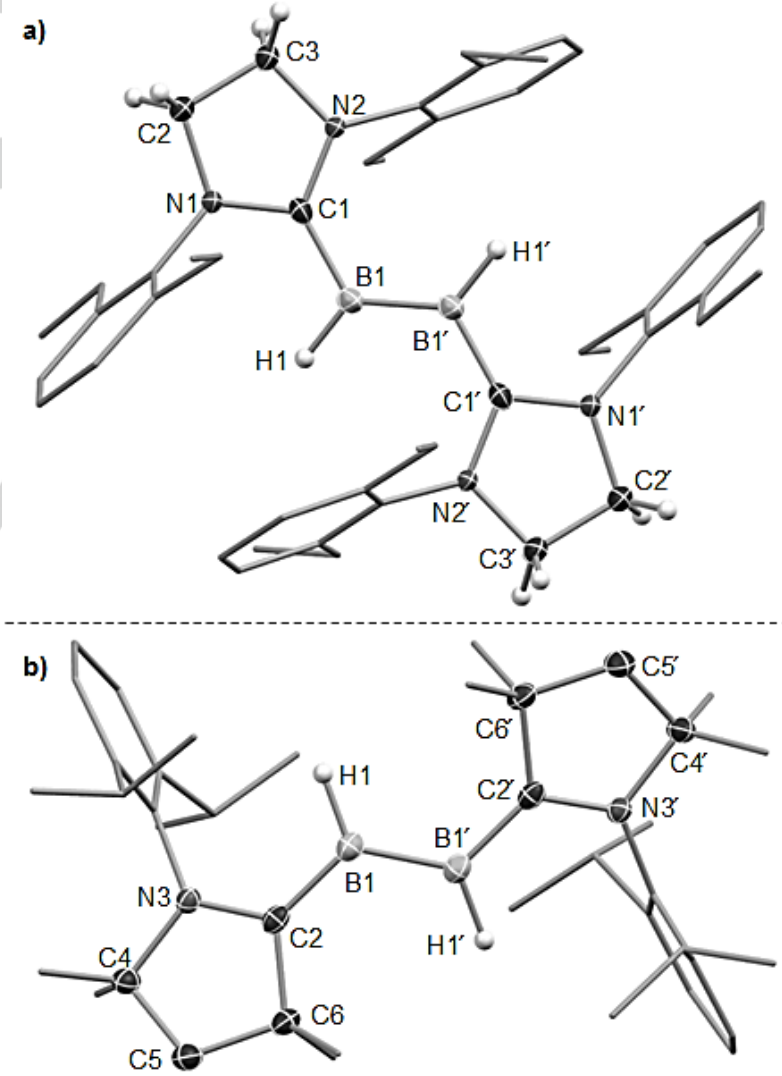

Figure 1. Crystallographically determined solid-state structures of a) 6 and b) 7. Thermal ellipsoids are set at $50 \%$ probability and have been omitted for the ligand periphery. Hydrogen atoms omitted except for boron-bound hydrides and backbone methylene protons in $\mathbf{6}$.

Recrystallization from pentane yielded purple crystals of compound $\mathbf{6}$ (75\% isolated yield) suitable for X-ray crystallographic analysis. The boron-bound hydrides could be located in the difference Fourier map and freely refined. Rather than being $C_{2}$-symmetric like diborene 7, diborene 6 is centrosymmetric and presents a planar $(\mathrm{C} 1 \mathrm{~B} 1 \mathrm{H} 1)_{2}$ core 
with a trans-conformation (Fig. 1a). The plane of the SIDep ligand framework forms a ca. $28^{\circ}$ angle with the core plane. Most notably, however, the B-B bond length [1.589(4) $\AA$ ] is only slightly elongated compared to that in the unsaturated derivative, $1[1.560(18) \AA],{ }^{[21]}$ while the $\mathrm{B}-\mathrm{C}_{\text {carbene }}$ bond $[1.529(3) \AA]$ is slightly shortened [ 1 $1.543(15) \AA],{ }^{[21]}$ in agreement with the slightly more $\pi$-acidic nature of SIDep compared to IDip. ${ }^{[26]}$

A comparison of the reactivity of $\mathbf{3 a - b}, \mathbf{4 a - b}$ and $\mathbf{5}$ towards $\mathrm{H}_{2}$ indicates a subtle interplay of electronic and steric factors: whereas unsaturated NHCs prevent $\mathrm{H}_{2}$ addition independent of steric demands, the slightly more $\pi$-acidic saturated NHCs do allow for hydrogenation, albeit only slowly and at elevated temperatures, provided that the ligands are not too sterically demanding. In contrast, strongly $\pi$ accepting and sterically much less demanding cAAC ligands promote facile $\mathrm{H}_{2}$ addition at room temperature. Once more these observations follow the trend that $\mathrm{L}_{2} \mathrm{~B}_{2}$ species supported by saturated NHCs display intermediate properties between those of diborynes stabilized by purely $\sigma$-donating unsaturated NHCs and diboracumulenes bearing highly $\pi$-accepting cAACs. Neither 6 nor 7 could be further hydrogenated to the corresponding tetrahydrodiborane(6) compounds.

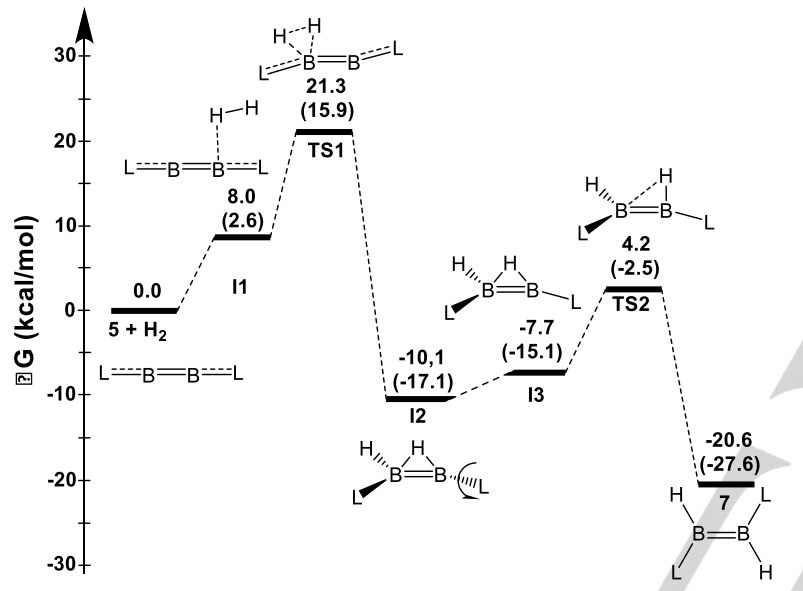

Figure 2. Calculated Gibbs energy profile of $\mathrm{H}_{2}$ addition to 5 at PCM-M05$2 X /$ def2-TZVPP//def2-SVP+G $G_{\text {corr }}$. The energies shown in parentheses are calculated at PCM-M05-2X/def2-TZVPP//def2-SVP+ZPE.

To elucidate the mechanism of $\mathrm{H}_{2}$ addition to compound 5 DFT calculations were carried out at PCM-M05-2X/def2-TZVPP//def2SVP level. The reported energies are corrected by zero-point-energy (ZPE) contributions and the thermal corrections to Gibbs free energy obtained at the PCM-M05-2X/def2-SVP level. Structural parameters of the calculated structures of $\mathbf{5}$ and $\mathbf{7}$ at this level of theory are in good agreement with the X-ray crystallographic data (Fig. S17). The calculated reaction profile is shown in Fig. 2. Theoretical data initially show very weak binding of $\mathrm{H}_{2}$ to one of the boron centers of the diboracumulene in I1. Subsequent hydrogen splitting proceeds via TS1 $\left(\Delta \mathrm{G}^{\ddagger}=21.3 \mathrm{kcal} \mathrm{mol}^{-1}\right)$ to yield the hydride-bridged intermediate 12. Rotation of one of the cAAC ligands around the $\mathrm{B}-\mathrm{C}_{\text {carbene }}$ axis in I2 forms its rotamer I3. Finally, the rearrangement of the bridging hydrogen atom via TS2 $\left(\Delta \mathrm{G}^{*}=14.3 \mathrm{kcal} \mathrm{mol}^{-1}\right.$; with respect to I2) yields diborene 7 (see Supporting Information for details). The overall reaction yielding 7 is exothermic by $20.6 \mathrm{kcal} \mathrm{mol}^{-1}$. The results show that the proposed mechanism of the $\mathrm{H}_{2}$ activation is very similar to that calculated for amido-substituted ditetrylynes. ${ }^{[27]}$ Analysis of the KohnSham molecular orbitals shows that the HOMO-9 of 6 and HOMO-8 of 7, the B-H $\sigma$-bonding orbitals, are polarized toward the hydrogen atoms, suggesting hydridic character (Fig. S18). In order to further assess the degree of hydricity, comparison was made with the NBO partial charge of the hydrides in $\mathrm{BH}_{3}(-0.104)$. In the cases of $\mathbf{6}$ and 7 NBO analysis provided a partial charge of -0.034 and -0.048 for $\mathrm{H} 1$, respectively, indicating a relatively weaker hydricity compared with $\mathrm{BH}_{3}$.

In conclusion, we have achieved the first uncatalyzed hydrogenation of first row main-group multiple bonds, providing a rational and selective synthetic route to carbene-stabilized 1,2dihydrodiborenes, previously only accessible in low yields from $\mathrm{LBBr}_{3}$ reductions. The feasibility of this reaction depends on the electronic and steric properties of the supporting carbene ligands. Theoretical data show an asynchronous two-step addition mechanism via a 1-( $\eta^{1}$-hydro)-1,2-( $\mu^{2}$-hydro $)$ diborene intermediate (I2).

\section{Acknowledgements}

We acknowledge the Alexander von Humboldt Foundation (Research Fellowship for Postdoctoral Researchers to Dr. M. Arrowsmith). This project has received funding from the European Research Council (ERC) under the European Union Horizon 2020 Research and Innovation Program (grant agreement no. 669054).

Keywords: diborenes $\cdot$ carbenes $\cdot$ hydrogenation $\cdot$ main-group chemistry $\bullet$ reaction mechanism

[1] P. Sabatier, J.-B. Senderens, Compt. Rend. 1899, 128, 1173-1176.

[2] P. Pollak, Fine Chemicals: the Industry and the Business, 2011, John Wiley \& Sons, New York.

[3] a) S. Nishimura, Handbook of Heterogeneous Catalytic Hydrogenation for Organic Synthesis, 2001, John Wiley \& Sons, New York; b) The Handbook of Homogeneous Hydrogenation, Eds. J. G. de Vries, C. J. Elsevier, 2007, Wiley-CH Verlag.

[4] a) G. C. Welch, R. R. San Juan, J. D. Masuda, D. W. Stephan, Science 2006, 314, 1124-1126; b) J. Paradies, Angew. Chem. 2014, 126, 3624-3629; Angew. Chem. Int. Ed. 2014, 53, 3552-3557.

[5] D. Wang, D. Astruc, Chem. Rev. 2015, 115, 6621-6686.

[6] S. Vasireddy, B. Morreale, A. Cugini, C. Song, J. J. Spivey, Energy Environ. Sci. 2011, 4, 311-345.

[7] C. Rüchardt, M. Gerst, J. Ebenhoch, Angew. Chem. Int. Ed. Engl. 1997, 36, 1406-1430.

[8] D. Leow, Y.-H. Chen, T.-H. Hung, Y. Su, Y.-Z. Lin, Eur. J. Org. Chem. 2014, 7347-7352.

[9] G. Zhong, B. Chan, L. Radom, J. Am. Chem. Soc. 2007, 129, 924-933.

[10] G. H. Spikes, J. C. Fettinger, P. P. Power, J. Am. Chem. Soc. 2005, 127, 12232-12233.

[11] T. J. Hadlington, M. Hermann, J. Li, G. Frenking, C. Jones, Angew. Chem. 2013, 125, 10389-10393; Angew. Chem. Int. Ed. 2013, 52, 10199-10203.

[12] a) Y. Peng, B. D. Ellis, X. Wang, P. P. Power, J. Am. Chem. Soc. 2008, 130, 12268-12269; b) Y. Peng, M. Brynda, B. D. Ellis, J. C. Fettinger, E. Rivard, P. P. Power, Chem. Commun. 2008, 6042-6044; c) Z. Zhu, X. Wang, Y. Peng, H. Lei, J. C. Fettinger, E. Rivard, P. P. Power, Angew. Chem. 2009, 121, 20652068; Angew. Chem. Int. Ed. 2009, 48, 2031-2034; d) C. A. Caputo, J. Koivistoinen, J. Moilanen, J. N. Boynton, H. M. Tuononen, P. P. Power, J. Am. Chem. Soc. 2013, 135, 1952.

[13] G. D. Frey, V. Lavallo, B. Donnadieu, W. W. Schoeller, G. Bertrand, Science 2007, 316, 439-441.

[14] F. Dahcheh, D. Martin, D. W. Stephan, G. Bertrand, Angew. Chem. 2014, 126, 13375-13379; Angew. Chem. Int. Ed. 2014, 53, 13159 -13163.

[15] a) H. Braunschweig, R. D. Dewhurst, S. Mozo, Chem. Cat. Chem. 2015, 54, 1630-1638; b) H. Braunschweig, R. Shang, Inorg. Chem. 2015, 54, 3099-3106; c) H. Braunschweig, R. D. Dewhurst, Angew. Chem. 2013, 125, 3658-3667; Angew. Chem. Int. Ed. 2013, 52, 3574-3583.

[16] a) H. Braunschweig, R. D. Dewhurst, C. Hörl, A. K. Phukan, F. Pinzner, S. Ullrich, Angew. Chem. 2014, 126, 3305-3308; Angew. Chem. Int. Ed. 2014, 53, 3241-3244; b) H. Braunschweig, C. Hörl, Chem. Commun. 2014, 50, 10983-10985.

[17] H. Braunschweig, T. Dellermann, W. C. Ewing, T. Kramer, C. Schneider, S. Ullrich, Angew. Chem. 2015, 127, 10409-10413; Angew. Chem. Int. Ed. 2015, 54,10271-10275. 
[18] a) J. Böhnke, H. Braunschweig, T. Dellermann, W. C. Ewing, T. Kramer, I. Krummenacher, A. Vargas, Angew. Chem. 2015, 127, 4551-4555; Angew. Chem. Int. Ed. 2015, 54, 4469-4473; b) J. Böhnke, H. Braunschweig, T. Dellermann, W. C. Ewing, K. Hammond, T. Kramer, J. O. C. Jimenez-Halla, J. Mies, Angew. Chem. 2015, 127, 14006-14010; Angew. Chem. Int. Ed. 2015, 54, 13801-13805.

[19] H. Braunschweig, T. Dellermann, R. D. Dewhurst, W. C. Ewing, K. Hammond, J. O. C. Jimenez-Halla, T. Kramer, I. Krummenacher, J. Mies, A. K. Phukan, A. Vargas, Nat. Chem. 2013, 5, 1025-1028.

[20] M. Arrowsmith, J. Böhnke, H. Braunschweig, M. Ali Celik, C. Claes, W. C. Ewing, I. Krummenacher, K. Lubitz, C. Schneider, Angew. Chem. Int. Ed. 2016, accepted.

[21] a) Y. Wang, B. Quillian, P. Wei, C. S. Wannere, Y. Xie, R. B. King, H. F. Schaefer III, P. v. R. Schleyer, G. H. Robinson, J. Am. Chem. Soc. 2007, 129 , 12412-12413; b) Y. Wang, B. Quillian, P. Wei, Y. Xie, C. S. Wannere, R. B. King, H. F. Schaefer III, P. v. R. Schleyer, G. H. Robinson, J. Am. Chem. Soc. 2008, 130, 3298-3299.

[22] H. Braunschweig, R. D. Dewhurst, K. Hammond, J. Mies, K. Radacki, A. Vargas, Science 2012, 336, 1420-1422.

[23] J. Böhnke, H. Braunschweig, P. Constantinidis, T. Dellermann, W. C. Ewing, I. Fischer, K. Hammond, F. Hupp, J. Mies, H.-C. Schmitt, A. Vargas, J. Am. Chem. Soc. 2015, 137, 1766-1769.

[24] J. Böhnke, H. Braunschweig, W. C. Ewing, C. Hörl, T. Kramer, I. Krummenacher, J. Mies, A. Vargas, Angew. Chem. Int. Ed. 2014, 53, 9082 9085; Angew. Chem. 2014, 126, 9228-9231.

[25] a) V. Lavallo, Y. Canac, C. Präsang, B. Donnadieu, G. Bertrand, Angew. Chem. 2005, 117, 5851-5855; Angew. Chem. Int. Ed. 2005, 44, 5705-5709; b) K. Chandra Mondal, S. Roy, B. Maity, D. Koley, H. W. Roesky, Inorg. Chem. 2016, 55, 163-169.

[26] Most recent review: D. J. Nelson, S. P. Nolan, Chem. Soc. Rev. 2013, 42, 6723-6753.

[27] M. Hermann, C. Goedecke, C. Jones, G. Frenking, Organomet. 2013, 32, 6666-6673. 


\section{Entry for the Table of Contents}

\section{COMMUNICATION}

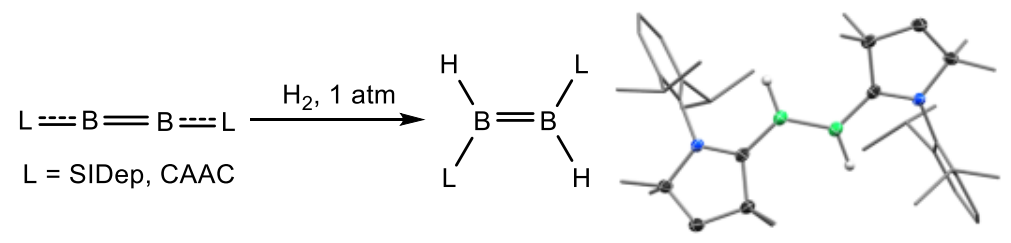

No catalyst needed: Two new carbene-stabilized 1,2-dihydrodiborenes have been synthesized by the direct and selective monohydrogenation of boron-boron multiple bonds under mild conditions. Theoretical calculations show a two-step asynchronous $\mathrm{H}_{2}$ addition mechanism proceeding via a bridging hydride.
M. Arrowsmith, J. Böhnke, $H$.

Braunschweig, * M. A. Celik, T. Dellermann and K. Hammond

Page No. - Page No.

Uncatalyzed Activation of Molecular Hydrogen by Low-Valent Diboron Species 